\title{
Atuação do psicólogo no processo de envelhecimento
}

\section{The psychologist role in the aging process}

\author{
Kamila de Souza Alves ${ }^{\dagger}$, Sabrina Caetano Trindade ${ }^{\dagger}$, Fátima Niemeyer da Rocha ${ }^{\text {}^{*}}$
}

Como citar esse artigo. ALVES, K.S; TRINDADE, S.C; DA ROCHA, F.N. Atuação do psicólogo no processo de envelhecimento. Revista Mosaico, v.11, n.1, p. 99-104, 2021

\author{
Resumo
}

Envelhecer é um decurso natural, constituído por alterações em diferentes aspectos da vida, em que surgem diversos desafios nos aspectos biológicos, psicológicos e sociais. Nessa perspectiva, o artigo objetivou abordar a atuação do psicólogo no processo de envelhecimento, a fim de promover o bem-estar do indivíduo que envelhece e auxiliar no enfrentamento das mudanças que esse processo envolve. Para tal, realizou-se uma revisão da literatura especializada quanto aos aspectos sócio-históricos da velhice, as teorias do envelhecimento, os desafios que surgem nesse processo, bem como sobre as possibilidades de atuação do psicólogo nesse contexto. Destacou-se a importância do trabalho desse profissional que contribui para um envelhecer ativo e saudável, promovendo uma melhor qualidade de vida, além de auxiliar na compreensão das dificuldades que a velhice pode causar nos idosos.

Palavras-chave: Envelhecimento. Desafios da velhice. Atuação do Psicólogo.

\begin{abstract}
Aging is a natural course, constituted by changes in different aspects of life, in which several challenges arise in biological, psychological and social aspects. In this perspective, the article aimed to address the psychologist's role in the aging process, in order to promote the well-being of the aging individual and assist in coping with the changes that this process involves. To this end, a review of the specialized literature was carried out regarding the socio-historical aspects of old age, the theories of aging, the challenges that arise in this process, as well as about the possibilities of the psychologist's performance in this context. The importance of the work of this professional was highlighted which contributes to an active and healthy aging, promoting a better quality of life, in addition to assisting in understanding the difficulties that old age can cause in the elderly.

Keywords: Aging. Challenges of old age. Psychologist performance.
\end{abstract}

\section{Introdução}

Ainda não há um consenso sobre quando a fase de envelhecimento se inicia, mas é notório a velhice populacional, em todas as camadas sociais. Contudo, conforme o Estatuto do Idoso Brasileiro (BRASIL, 2003) considera-se idoso o indivíduo com idade igual ou superior a sessenta anos.

Estudos desenvolvidos sobre o tema sugerem que o envelhecimento pode ser classificado em três eixos: psicológico, biológico e social. No eixo psicológico destaca-se o medo da morte, da solidão e como lidar com as perdas. No eixo biológico são colocadas as mudanças do corpo, como cabelos brancos, redução da estatura, rugas, modificações sensoriais, entre outros. E no eixo social são tratadas as rejeições no campo de trabalho e as relações interpessoais.

Assim percebe-se que, com o envelhecimento, a pessoa se depara com mudanças em diferentes aspectos da sua vida. A ausência do autocontrole, os impedimentos de realizar afazeres do dia a dia, a ausência de ente queridos e a proximidade da morte são questões que ameaçam o bem-estar do indivíduo e isso pode acarretar em sentimentos de medo, tristeza, sensação de inferioridade no seu ambiente familiar, de solidão e problemas de saúde mental.

Diante desse cenário, cada vez mais a Psicologia vem trabalhando para promover o bem-estar do idoso, auxiliando no enfrentamento das mudanças que acompanham o processo de envelhecimento, afinal é importante saber lidar com essas alterações almejando encontrar um equilíbrio entre as perdas e ganhos nessa

\footnotetext{
Afiliação dos autores:

${ }^{\dagger}$ Graduanda, Curso de Psicologia, Universidade de Vassouras, Vassouras, RJ, Brasil

* Doutora em Psicologia, Professora Titular, Curso de Psicologia, Universidade de Vassouras, Vassouras, RJ, Brasil
}

* Email de correspondencia: fatimaniemeyer@hotmail.com 
nova etapa.

Nesta perspectiva, o presente artigo tem como objetivo apresentar algumas reflexões sobre o impacto que o processo de envelhecimento causa no idoso e tem a proposta de abordar como o psicólogo pode atuar de forma colaborativa neste processo, trabalhando as necessidades do paciente, considerando sua vulnerabilidade biopsicossocial.

Este estudo constitui uma revisão de literatura a respeito dos aspectos sócio-históricos da velhice, das teorias do envelhecimento, os desafios desse processo, bem como a atuação do psicólogo frente a essas vulnerabilidades. Utilizou-se para a pesquisa artigos publicados pela Revista Portuguesa de Ciências do Desporto, Geriatria \& Gerontologia, Mneme: Revista de Humanidades, Revista Brasileira de Ciências do Envelhecimento Humano e Revista Brasileira de Medicina do Esporte, além de trabalho de conclusão de curso, sendo escolhidos estudos publicados entre 2002 e 2014.

Após a seleção dos artigos, foram seguidos, nessa ordem, os seguintes passos: leitura exploratória; leitura seletiva e escolha do material que se adequam aos objetivos e tema deste estudo, leitura analítica e análise dos textos, finalizando com a realização de leitura interpretativa e, por fim, a escrita. O presente trabalho constituiu-se agrupando os temas mais abordados nas seguintes categorias: aspectos sócio-históricos da velhice, teorias do envelhecimento, os desafios do processo de envelhecimento e a atuação do psicólogo no processo de envelhecimento.

\section{Aspectos sócio-históricos da velhice}

A sociedade demarca a velhice em dois principais pontos: a própria idade cronológica e a saída do mercado de trabalho, como afirma Mascaro (1997 apud OLIVEIRA et al., 2009).

$\mathrm{Na}$ Antiguidade, o valor atribuído aos idosos variava conforme a tribo à qual pertenciam. Em muitos rituais impostos nas tribos, os idosos não eram bem quistos e eram mortos ou abandonados, sendo que muitos desses rituais eram considerados como motivo de festa pela comunidade. Nas ilhas Fidji, por exemplo, os velhos eram considerados incapazes de realizar qualquer atividade e, desta forma, se suicidavam; entre os dinkas, enterrar os velhos vivos era tradição; nos povos ainos, fangs e tongas do Japão, eram afastados da vida pública; entre os hopis, índios creek e crow, bosquímanos da África do Sul, estes eram abandonados em uma cabana apenas com água e comida. (BEAUVOIR, 1990, apud OLIVEIRA et al., 2009). Porém um aspecto que perpassa todas as civilizações é que apenas os velhos mais abastados social e economicamente é que eram vistos como sábios e líderes. (MASCARO, 1997 apud
OLIVEIRA et al., 2009)

$\mathrm{Na}$ Idade Média, muitos homens morriam cedo e era raro as pessoas ultrapassarem o limite da vida adulta, logo, poucos passavam dos 50 anos. Quando os homens que ultrapassavam essa idade eram detentores de riquezas, eram valorizados e chefes da família, assim, o valor não era atribuído à longevidade, mas às posses. Por sua vez, para as mulheres só restavam a solidão, viuvez e a pobreza. (MASCARO, 1997, apud OLIVEIRA et al., 2009)

Oliveira pontua que a sociedade atual ainda enxerga os idosos da mesma forma como ocorria no período da Revolução industrial e do início do capitalismo:

Durante os séculos XVI ao XIX os idosos continuaram sendo marginalizados, principalmente com o advento da Revolução Industrial e do Capitalismo. Surgem, assim, a população do trabalho e do lucro; logo, quem não trabalha, não produz, é colocado à margem da sociedade. É o que acontece com os idosos aposentados nos dias de hoje. (OLIVEIRA et al., 2009, p. 425)

$\mathrm{Na}$ atualidade, percebe-se que é negado ao velho sua função social, tal qual habilidades como aconselhar e lembrar, tratando-se de mecanismos não valorizados, sendo decorrente a opressão à velhice. Isso torna-se visível a partir de equipamentos institucionais como as casas de 'repouso' e asilos, por questões psicológicas como a tutelagem, a inexistência do diálogo e a discriminação e por estudos científicos que demonstram uma deterioração física e nas relações interpessoais. (CHAUÍ, 1994 apud ARAUJO et al., 2005)

Ou seja, o número de pessoas que atingiam o que hoje pode ser considerada velhice era pouco representativo, pois as pessoas morriam muito cedo em virtude das doenças e das condições precárias de existência. Porém, as que conseguiam atingir esse estágio do ciclo da vida, por um largo espaço de tempo eram associadas a limitações e deficiências, sendo caracterizadas como pouco produtivas e, assim, eram levadas a morte ou abandonadas. Contudo, nota-se que aquelas detentoras de posses e riquezas eram valorizadas.

\section{Teorias do envelhecimento}

Embora a idade entre 60 e 65 anos ser designada como o marco para o início do envelhecimento, as pessoas não ficam velhas ou envelhecem em uma idade específica, pois o envelhecimento é um processo contínuo e gradual de alterações naturais que começam na idade adulta. Logo, as mudanças que constituem e influenciam o envelhecimento são complexas.

O estudo dos fenômenos fisiológicos, psicológicos e sociais relacionados ao envelhecimento do ser humano é considerado um campo interdisciplinar com reflexões 
importantes acerca da velhice, não apenas por médicos, mas também por pesquisadores, cientistas e estudiosos em geral, visando contribuir para o entendimento do processo de envelhecimento como aquele que possui características variadas e peculiares.

Com o progresso dos estudos e pesquisas na área de Gerontologia, diversas teorias acerca do envelhecimento foram formuladas, tanto de bases biológicas, quanto as fundamentadas nas perspectivas sociais e psicológicas.

As teorias biológicas do envelhecimento examinam o assunto sob a ótica do declínio e da degeneração da função e estrutura dos sistemas orgânicos e das células e tendem a focalizar nos problemas que afetam a precisão do sistema orgânico durante o processo de envelhecimento, sejam eles de origem genética, metabólica, celular ou molecular. (FARINATTI, 2002).

Apesar dasinúmeras definições de envelhecimento biológico divergir segundo a orientação teórica, "comungam a noção de perda de funcionalidade progressiva com a idade, com o consequente aumento da susceptibilidade e incidência de doenças, aumentando a probabilidade de morte." (MOTA et al., 2004, p. 82).

As teorias biológicas podem ser divididas em duas categorias: Teorias Genéticas e Teorias Estocásticas. As teorias genéticas sugerem que a velocidade do fenômeno de envelhecimento é condicionada por fatores genéticos. Já as estocásticas trabalham com a hipótese de que o envelhecimento dependeria do acúmulo de lesões em moléculas vitais, associadas às agressões ambientais, que provocam um declínio fisiológico progressivo. Farinatti (2002) afirma que ambas as categorias carecem de comprovação definitiva; assim surgem muitas dúvidas sobre a real influência e interação das causas por elas apontadas no processo global de envelhecimento biológico.

As teorias sociológicas do envelhecimento analisam as influências históricas, econômicas, etnográficas, culturais e sociais que influenciam a velhice (SIQUEIRA, 2001 apud LYRA, 2014, p. 37). São classificadas segundo seu nível de análise em macrossocial, microssocial e micro/macrossocial.

As teorias macrossociais examinam as influências das estruturas sociais nas experiências e comportamentos. No nível microssocial, o foco é o organismo individual, isto é, o indivíduo e suas interações sociais. No micro/ macro, estão as teorias que abrangem os dois níveis de análise simultaneamente. (LYRA, 2014, p. 37-38)

Dividem-se também em três gerações, de acordo com suas origens intelectuais: a primeira geração é composta pelas teorias elaboradas entre 1949 e 1969 , as da segunda, entre 1970 e 1980 e da terceira, a partir de 1980 .

Algumas teorias da primeira geração sugerem, em relação a interação social:

1. O bem-estar na velhice seria consequência da resistência ao desengajamento social, enfatizando a necessidade benéfica da atividade social entre os velhos.

2. O envelhecimento seria um processo inevitável de desengajamento, ou seja, de diminuição da interação entre o indivíduo e seu sistema social.

3. os idosos desenvolvem uma cultura própria baseada em seus interesses e crenças comuns, fomentada pela exclusão social e pela política segregacionista a qual agrupa os idosos em um mesmo contexto.

As teorias da segunda geração relatam que crises, como viuvez, perda de saúde e de papéis sociais formam uma espiral de respostas negativas em relação à senescência e acabam provocando um rótulo de dependência do idoso em relação ao ambiente, à família ou a profissionais.

A da terceira geração propõe que a estrutura social e as políticas públicas constrangem oportunidades, escolhas e experiências na velhice e a perda de poder e de autonomia com o envelhecimento são consequências da influência de restrições econômicas e políticas.

Por fim, as teorias psicológicas buscam analisar as mudanças nos "desempenhos cognitivos, afetivos e sociais, bem como as alterações em motivações, interesses, atitudes e valores que são característicos dos anos mais avançados da vida e dos anos da velhice" (FALCÃO; CACHIONI; YASSUDA, 2009 apud LYRA, 2014, p. 26).

O esforço científico concentra-se no uso de teorias para explicação de aspectos específicos do envelhecimento, estratégias de enfrentamento ao estresse, geratividade e relações recíprocas entre o self e a sociedade na construção do envelhecimento. (LYRA, 2014, p. 36)

As teorias psicológicas contemporâneas do envelhecimento dispõem o seguinte, conforme relatado por Lyra (2014, p. 36):

1. Existe uma inter-relação ativa no processo de construção do mundo social entre o indivíduo e o ambiente. Assim, a redução da amplitude de redes de relações sociais e participação social na velhice reflete um mecanismo de adaptação, de redistribuição dos recursos socioemocionais frente à limitação temporal dos idosos. As relações socialmente próximas são mantidas, pois, oferecem experiências mais significativas. Essa teoria defende que os idosos moldam seu ambiente com o objetivo de maximizar afetos positivos e diminuir os negativos, metas úteis para uma velhice bem-sucedida;

2. A dependência não é uma característica da velhice, mas ocorre durante toda a vida. Os valores culturais se refletem na relação das pessoas com a dependência, seu significado e sua aceitação.

Diante do exposto, percebe-se que as abordagens das teorias apresentadas contribuem para entender como 
o indivíduo se adapta ao estado de idoso e explicar a forma como ocorre o seu processo de envelhecimento.

\section{Desafios do envelhecimento}

Envelhecer pode gerar a necessidade de uma retrospectiva da vida. Essa percepção acerca de sua trajetória existencial, onde pondera-se as conquistas e os arrependimentos, contribuirá para o quanto o idoso experimentará o "desespero". Erikson (1963 apud LIMA et al., 2011, p. 263) afirma que "esse "desespero" expressa o sentimento de que o tempo agora é curto demais para recomeçar e tentar outros caminhos."

Assim, o primeiro desafio "corresponde à capacidade em equilibrar a coerência e a plenitude pessoais com o desespero perante a finitude e a proximidade da morte, além de aceitar falhas e omissões do passado." (ERIKSON, 1986 apud LIMA et al., 2011, p. 263).

Outro aspecto destacado por Erikson (1998 apud LIMA et al., 2011) é o conflito entre a produtividade e a estagnação. A participação na vida dos filhos e dos netos, a oportunidade de ensinar algo para as próximas gerações, realizar atividade cotidianas, fazer pequenos reparos na casa, além da manutenção de atividades laborativas e atividades físicas e de lazer, tem o potencial de reforçar o senso de produtividade. Assim, esta tem a função de auxiliar o idoso a sentir-se vivo e encontrar satisfação na velhice; mas a sua falta ou carência gera sintomas psicopatológicos no indivíduo que envelhece, aumentando a força do "desespero" e a contínua sensação de estagnação.

Apesar de todos os esforços do indivíduo em manter a produtividade, o corpo continua a perder, gradativamente, a autonomia e as habilidades físicas, por conseguinte, com a perda da independência, a autoestima e a segurança podem também enfraquecer.

Mais um desafio é a perda de pessoas queridas, pois adquirir um novo senso de mutualidade e companheirismo com outras pessoas torna-se algo doloroso e difícil. Jerusalinsky (2001 apud LIMA et al., 2011) afirma que, em muitos casos, a perda do cônjuge ou de amigos significativos é como ter perdido parte de si mesmo, pois estes foram testemunhas da sua existência, construíram e mudaram, em conjunto, a realidade, tornando-se cúmplices de um existir.

E a última crise pode ocorrer após os 80 anos, que se expressa como forma de preocupação com o mundo e o universo, com o futuro das próximas gerações, com o significado da existência humana, assim como a reafirmação ou reformulação de princípios religiosos que estiveram presentes na vida do indivíduo (Erikson et. al., 1986, apud LIMA et al., 2011).

Assim, o idoso é desafiado a se inspirar em sua trajetória para extrair os componentes que precisa para enfrentar a velhice. Além disso, à medida que a sociedade não consegue valorizar o idoso proporcionando-lhe um ambiente saudável e motivador, a velhice se torna ainda mais difícil, não só para ele, mas para os demais membros da comunidade. Logo usufruir os anos finais da vida com satisfação envolverá, portanto, a presença de fatores pessoais e sociais.

\section{Atuação do psicólogo no processo de envelhecimento}

Com o envelhecimento, ocorre uma série alterações emocionais, psíquicas, físicas e sociais, sendo importante saber lidar com essas modificações para encontrar o bem-estar nessa etapa.

A forma com que o idoso lidará com essas questões contribuirá de forma positiva ou negativa para a sua qualidade de vida. Porém, nem sempre é fácil assimilar, trabalhar e aceitar todas as transformações sozinho. Assim, a Psicologia, neste contexto, atua para promover o bem-estar do idoso, auxiliando no enfrentamento das mudanças que acompanham esse processo.

Quanto a Psicologia do Envelhecimento, Néri (2004, p. 72-73) afirma:

\begin{abstract}
A psicologia do envelhecimento focaliza as mudanças nos desempenhos cognitivos, afetivos e sociais, bem como as alterações em motivações, interesses, atitudes e valores que são característicos dos anos mais avançados da vida adulta e dos anos da velhice. Enfoca as diferenças intraindividuais e interindividuais que caracterizam os diferentes processos psicológicos na velhice, levando em conta os desempenhos de diferentes grupos de idade e sexo e de grupos portadores de diferentes bagagens educacionais e socioculturais. Estuda também os processos e as condições problemáticas que caracterizam e que afetam o funcionamento psicológico dos indivíduos mais velhos.
\end{abstract}

A colaboração da Psicologia refere-se, assim, à compreensão do processo de envelhecimento, à avaliação comportamental e à reabilitação por meio de um conjunto de técnicas, de diagnóstico, de avaliação e de intervenção voltadas ao tratamento dos problemas comportamentais e psicológicos que afetam o funcionamento e o bem-estar dos idosos. Esses métodos podem ser aplicados em diversas áreas, como pode ser observado no que é proposto por Néri (2004, p. 75) quanto aos campos de aplicação dos serviços psicológicos à idosos:

1. Saúde - Ênfase em promoção da saúde; reabilitação cognitiva e psicomotora; aconselhamento, orientação e psicoterapia; avaliação de capacidades funcionais; apoio psicológico em situação de reabilitação física e de cuidados paliativos; treino de memória; psicoterapias em desordens emocionais; treino de relaxamento; terapias expressivas e arte-terapia em demência. 
2. Família - Oferecer informação e apoio à promoção de boas relações e de relações de interdependência entre as gerações, atuar em situações de crise e oferecer apoio psicológico.

3. Instituições públicas e privadas de assistência social e à saúde dos idosos - Oferecer treinamento de habilidades profissionais e apoio psicológico a profissionais que trabalham com idosos, assessoria ao planejamento e à avaliação de serviços.

4. Educação, lazer e sociabilidade - Oferecer informação psicológica e atividades grupais visando ao aprimoramento de habilidades sociais, atuar no planejamento do currículo e fazer pesquisa. Também, pela organização e orientação de centros de memória, grupos de avós, de contadores de história e de voluntários, clubes recreativos, centros de convivência e programas de autogestão por idosos, no trabalho, no lazer ou na ação social.

5. Trabalho - Ajudar com programas de capacitação e reciclagem para o trabalho, treino de atitudes e motivação. Operar em favor dos mais velhos, desenvolvendo instrumentos e técnicas de seleção, acompanhando providências no campo da ergonomia, trabalhando na prevenção de riscos e promovendo alterações na cultura organizacional de modo a favorecer o aproveitamento das competências dos idosos. Trabalhar atitudes e procedimentos de pessoal de recursos humanos para lidar com os trabalhadores mais velhos. Auxiliar os idosos a flexibilizar a carreira, a desenvolver papéis profissionais adequados aos ganhos da maturidade, a planejar uma segunda carreira ou a preparar-se para a aposentadoria.

6. Ambiente ecológico - Os focos são a segurança, o conforto e a satisfação nas cidades, nos lares e nas instituições, fatores que contribuem para a boa qualidade de vida objetiva e subjetiva dos idosos.

7. Situações de vulnerabilidade social - Contribuir para programas de prevenção e de atendimento à pobreza; à violência, ao abandono e aos maus-tratos; à deficiência física, mental e sensorial.

Nesse contexto, podem-se listar como principais funções dos psicólogos especializados em oferta de serviços à idosos, segundo Néri (2004, p. 76):

1. Avaliação psicológica;

2. Planejamento e execução de intervenção psicológica;

3. Orientação e aconselhamento;

4. Informação e mudança de atitudes em relação à velhice;

5. Psicoterapias individuais e grupais com idosos, voltadas para problemas de ordem emocional e psicossocial;

6. Tratamento de déficits e de distúrbios cognitivos e psicomotores, ou reabilitação cognitiva dos idosos;

7. Orientação, aconselhamento e psicoterapia, individuais e grupais, a familiares de idosos dependentes e fragilizados;

8. Intervenções individuais e grupais em situações de crise;

9. Assessoria a instituições públicas, a organizações públicas e privadas que amparam e cuidam de idosos e a famílias de idosos;

10. Assessoria, planejamento e execução de programas de promoção em saúde na comunidade e promoção social para idosos;

11. Assessoria e planejamento de providências ecológicas e de programas de mudança de atitudes visando ao bem-estar dos idosos, nas cidades, nas instituições e nas organizações;

12. Apoio psicológico a profissionais que cuidam de idosos;

13. Participação em equipes multiprofissionais.

Ademais, a Psicologia pode oferecer contribuições ao planejamento e à reprogramação ambiental para idosos independentes ou funcionalmente incapacitados, seja residencial, de trabalho, de asilos e casas de repouso, do bairro e da cidade, dos hospitais, dos ambulatórios, dos centros-dia e centros de saúde e dos locais de lazer e de convivência, a fim de proporcionar condições para que o idoso possa viver bem no seu ambiente (NÉRI, 2004, p. 78).

\section{Considerações Finais}

É possível notar, enfim, que a velhice por muito tempo foi socialmente associada a diversas limitações, deficiências e pouca produtividade, englobando, além disso, a expectativa do fim da vida, sendo por morte e/ou abandono. Percebe-se, ainda, que o processo de envelhecimento desenvolve-se em três áreas fundamentais: biológica, que resulta das mudanças operadas no organismo devido aos efeitos da idade avançada, fazendo com que o indivíduo perca a capacidade de manter o equilíbrio e diminuindo as funções fisiológicas; psicológica, que está associada à diminuição e alteração de faculdades psíquicas que podem resultar em dificuldade de adaptação aos novos papéis, em falta de motivação e dificuldade de planear o futuro; e social, que é relativa a mudanças nos papéis sociais no contexto em que o indivíduo está inserido.

Ao atingir a velhice, torna-se necessário e vital aceitar tanto a inalterabilidade do passado quanto o enigma do futuro; é importante reconhecer falhas e omissões passadas e equilibrar o consequente "desespero" com o senso de "integridade". Essas não são tarefas fáceis, principalmente quando o indivíduo não teve um ambiente psicossocial adequado e saudável. Neste contexto, a atuação do psicólogo que pode contribuir para que o indivíduo que envelhece possa responder adequadamente aos desafios do seu processo de envelhecimento. 
Nesta perspectiva, considerando a formação e os conhecimentos científicos adquiridos sobre o comportamento humano ao longo da vida, os psicólogos contribuem para um envelhecer ativo, saudável e no qual haja um bom envolvimento social, permitindo ao idoso manter e melhorar a sua qualidade de vida. Paralelamente, ajudam a compreender e a intervir nos problemas que o processo de envelhecimento causa nos idosos, tornando, assim, possível prevenir e tratar a dor e a doença.

\section{Referências}

ARAÚJO, Ludgleydson Fernandes de; CARVALHO, Virgí $\urcorner$ nia Ângela M. de Lucena e. Aspectos Sócio-Históricos e Psicológicos da Velhice. Mneme Revista de Humanidades, v. 6, n. 13, p. 01-09, jul. 2005.

BRASIL. Lei $n^{\circ} 10.741 / 2003$. Dispõe sobre o Estatuto do Idoso e dá outras providências. Brasília: DF, out. 2003.

FARINATTI, Paulo de Tarso Veras. Teorias biológicas do envelhecimento: do genético ao estocástico. Revista Brasileira de Medicina do Esporte. Niterói, v. 8, n. 4, p. 129-138, Jul/Ago, 2002.

LIMA, Priscilla Melo Ribeiro de; COELHO, Vera Lúcia Decnop; GÜNTHER, Isolda de Araújo. Envolvimento Vital: Um Desafio da Velhice. Geriatria \& Gerontologia, v. 5, n. 4, p. 261-268, jan. 2011.

LYRA, Mariana Carlos de Andrade. "Espelho, Espelho Meu": A percepção de idosas acerca do processo de envelhecimento. Trabalho de Conclusão de Curso (graduação em Serviço Social). Centro de Artes, Humanidades e Letras, Universidade Federal do Recôncavo da Bahia, Cachoeira, 2014.

MOTA, M. Paula; FIGUEIREDO, Pedro A.; DUARTE, José A. Teorias Biológicas do Envelhecimento. Revista Portuguesa de Ciências do Desporto, v. 4, n. 1, p. 81-110, jan. 2004

NERI, Anita Liberalesso. Contribuições da psicologia ao estudo e à intervenção no campo da velhice. Revista Brasileira de Ciências do Envelhecimento Humano, Passo Fundo, v. 1, n. 1, p. 69-80, jun. 2004.

OLIVEIRA, Sandra Carolina Farias de; SANTOS, Gláucia Lorena Guedes dos. Construção sócio-histórica e midiática da velhice. Revista Brasileira de Ciências do Envelhecimento Humano, v. 6, n. 3, p. 422-428, set. 2009. 